8 W. Ostwald, Elektrochemie, ihre Geschichte und Lehre. Akad. V. Ges., Leipzig 1896.

9 H. Schimank, Johann Wilhelm Ritter, der Begründer der wissenschaftlichen Elektrochemie. Abh. Ber. dt.Mus. 5, 175 (1933).

10 Worlds Who's Who in Science, p. 1428. Marquis, Chicago 1968.

11 J.W. Ritter, Denkschr. K. Akad. Wiss., München, 11, 254 (1811).

12 J.W. Ritter, Gilberts Annln. Phys. 7, 447 (1801).

13 Bibliographie Universelle, Paris, $B 8,136$ (1824).

14 Poggendorffs Annln. Naturwiss. Leipzig II 652 (1863).

15 A. Hermann, Die Begründung der Elektrochemie und Entdeckung der ultravioletten Strahlen. Akad. V. Ges. Frankfurt a.M. 1968.

16 H. Berg, Spektrum 12, 32 (1976).
17 H. Berg und D. Germann, in: Der junge Schelling, p. 83 H. Böhlaus Nachf., Weimar 1977.

18 P. Sue, Histoire du Galvanisme et Analyse. Bernard, Paris 1802.

19 E. Du Bois-Reymond, Untersuchungen über tierische Elektrizität, Berlin 1848/49.

20 S. Arrhenius, Z. physik. Chem. 1,631 (1887).

21 E. Hückel, Ergebn. exakt. Naturw. 3, 199 (1924).

22 Th. Shedlovsky, Proc. Symp. Electrochemistry in Biology and Medicine, New York 1953.

23 H. Berg, ed., Elektrochemische Prinzipien und Methoden in der Molekularbiologie. Akademie Verlag, Berlin 1966.

24 G. Milazzo, Ed, Rome. Vol.1-5 Birkhäuser, Basel 1974-1978; from vol. 6, Elsevier, Holland.

25 1st Gordon Conf. Bioelectrochemistry, 1980. Ed. N.H. Tilton.

\title{
Electrode technique
}

by William T. Bresnahan and Philip J. Elving

Department of Chemistry, University of Michigan, Ann Arbor (Michigan 48109, USA)

\section{Introduction}

The application of contemporary electrochemistry to the study of compounds and phenomena of biological significance is intimately connected with the role of specific electrode intervention in and response to such compounds and phenomena. Such application has ranged from the in vitro study of redox reactions involving small molecules occurring in biosystems to the in vivo study of the effects of the insertion of electrodes in damaged anatomical areas. Space allows only a cursory description of current lines of research involving the focal action of electrodes in bioelectrochemistry, which may itself be defined as the application of electrochemical principles, methodology and techniques in order to gain a better understanding of biologically relevant systems.

A recent development of great potential importance is that of modified electrodes to which biological compounds and species are attached for the purposes of better examining biological processes and of investigating electrochemical regeneration of the products of chemical and biochemical (e.g., enzymatic) reactions with respect to chemical processing and energy conversion.

With regard to electrodes, the commonly used potentiometric and voltammetric (including polarographic) techniques of measurement basically require an indicating or working electrode, which equilibrates with the chemical species of interest or engages in a faradaic process with it, and a reference electrode to which the potential developed at the indicating electrode or applied to the working electrode can be referred. If an appreciable current flow or IR drop is involved, a counter electrode can be advantageously added with the working and counter electrodes in the electrolysis loop while the working and reference electrodes are part of a potentiometric loop.

\section{Electrode types}

The indicating electrodes used in potentiometry may be zero class electrodes, which equilibrate with electron transfer-processes, e.g., platinum, graphite or mercury, or 1st class electrodes of metal which equilibrate with ions of that metal, e.g., a silver wire immersed in a $\operatorname{Ag}(\mathrm{I})$ solution. The latter type of electrode is readily converted in many cases to a 2nd or 3rd class electrode which, for example, responds to the activity of anions or cations which are involved in solubility or complex-formation equilibria with the 1st class electrode cation, e.g.,

2nd class electrode: $\mathrm{La}, \mathrm{LaF}_{3} / \mathrm{F}^{-}$

3rd class electrode: $\mathrm{Ag}, \mathrm{Ag}_{2} \mathrm{~S}, \mathrm{CuS} / \mathrm{Cu}^{++}$

Many selective ion electrodes are 2nd and 3rd class electrodes. Such potentiometric electrodes are well covered in the literature ${ }^{1-3}$.

Reference electrodes, whose primary requirement is that their potential is not appreciably altered on modest current flow, are well described by Ives and Janz ${ }^{4}$. Potentials subsequently cited, unless otherwise noted, are referred to the aqueous saturated calomel electrode (SCE).

Counter or auxiliary electrodes are generally of platinum, less frequently of some other noble metal or graphite, and are usually used in the form of wire spirals, rods, gauze or solid sheets. The area must be sufficiently large that the complementary faradaic process occurring at the counter electrode does not become rate-limiting.

Subsequent discussion is focussed on the working electrode as the latter is used to examine processes 
involving current flow due to faradaic and/or capacitive processes. Working electrodes are commonly of mercury, platinum or carbon (pyrolytic graphite; glassy or vitreous carbon; spectroscopic graphite). A wide variety of forms are used, e.g., the disk (made by sealing solid electrode material in a glass or plastic tube and then polishing the end surface smooth) is a favorite configuration and can be used stationary or rotating. Mercury is usually used as a dropping or hanging drop electrode.

The critical factors in controlling and then interpreting the voltammetric patterns obtained with a given working electrode may include a) the nature of the electrode material, electrode configuration used, and electrode treatment and conditioning (this is especially important for solid electrodes), b) the test medium composition (solvent; background electrolyte components; $\mathrm{pH}$; ionic strength), and c) the nature and operational characteristics of the technique used, including potential scan, polarization or scan rate $(\mathrm{dE} /$ $\mathrm{dt}$ ), and timing sequence for perturbation methods.

\section{The electrode/solution interface}

The structure of the electrode/solution interface and its role in faradaic and capacitive processes have been well summarized by Conway ${ }^{5}$ and Delahay ${ }^{6}$.

Adsorption on electrodes of nonelectroactive species as well as of electroactive species, reaction intermediates and products has been extensively studied since such studies are essential to the understanding of electrolytic processes. Adsorption is a very complex phenomenon which is only partially understood. All substances, when present in solution in sufficiently high concentrations, produce the measurable effects of adsorption, i.e., the displacement of solvent molecules and/or background electrolyte species from the interface.

Adsorption at electrodes differs from adsorption in a more general sense in that the electrical potential at the adsorbent surface is controllable, thus providing an additional manipulative energy parameter.

Although there are obvious differences between the living cell membrane as an electrically charged interface and the electrode/solution interface, both interfaces are similar in many respects. It is consequently often useful to study the reactions of biological compounds at an electrode interface where solution composition and applied potential are readily controlled. To utilize properly the electrochemical information, e.g., in considering the electrode/solution interface as a prototype for biological interfaces or, more generally, in attempting to transfer information and conclusions reached in electrochemical studies to biological situations, it is necessary to understand specific electrode/substrate phenomena; information obtained on adsorbate-adsorbate and adsorbate-adsorbent interactions may be directly applicable to biological situations. Account must also be taken of phenomena peculiar to heterogeneous reactions, e.g., chargetransfer rates and possible stereospecificity of reaction.

A possible result of obvious interest involves knowledge of the rates at which adsorption equilibria are established for various combinations of compounds, electrodes and experimental conditions.

\section{The polarographic-voltammetric electrode}

Adsorption phenomena. As noted, examination of adsorption at solution/electrode interfaces may yield information of value, e.g., concerning the behavior of nucleic acid species at electrically charged boundaries in the living cell and of coenzymes at charged interfaces with regard to surface activity, association and interaction in the adsorbed state, and electron transfer.

Advantageously used techniques include phase-selective alternating current polarography, e.g., in the absence of a faradaic process the quadrature current component is simply related to the interfacial differential capacity ${ }^{7}$, and inverse normal pulse polarography, e.g. a step from a potential at which a faradaic process does not occur to one at which such a process occurs produces a current proportional to the adsorbed species ${ }^{8}$.

Typical are studies of the adsorption at aqueous solution/mercury interfaces of adenine by $\mathrm{AC}$ polarography ${ }^{9}$ and pulse polarography ${ }^{8}$, and of large nucleic acid components by Berg ${ }^{10}$. Nürnberg ${ }^{11}$, Pale$\mathrm{cek}^{12}$, and their collaborators. Studies of the $\mathrm{NAD}^{+} /$ NADH redox couple ${ }^{13-15}$ resulted in optimization of the determination of NADH at $\mu$ mole to mmole-levels by oxidation at carbon and platinum electrodes ${ }^{16}$.

Redox and coupled chemical reactions. Mechanistic studies abound of electron-transfer reactions and of coupled chemical reactions at various types of voltammetric electrodes involving reactant, intermediate and product species of biological importance, ranging from small molecules, such as the nucleic acid bases, through intermediate molecules such as the pyridine coenzymes and vitamin $B$ species, to macromolecules such as DNA and RNA ${ }^{17-21}$. A number of analytical methods have resulted as by-products of such studies. Typical recent studies involve the electrochemically activated binding of polycyclic aromatic hydrocarbons to $\mathrm{DNA}^{22}$, the redox properties of nitrogenase ${ }^{23}$, and thin-layer spectroelectrochemical examination with optically transparent electrodes of redox enzymes $^{23}$ and of vitamin $B_{12}$ and related cobaloamins $^{23}$.

3 types of reaction kinetics have often been measured electrochemically ${ }^{24}$. One type involves homogeneous solution reactions, in which the bulk solution concentration of electroactive species is monitored. Another area of application involves the unique nature of 
polarographic techniques and is applicable to rapid reactions, which can be made to occur at the electrode surface, due to the disturbance of an equilibrium by electrolysis of one component and the resulting reestablishment of equilibrium, e.g., the use of suitably rapid relaxation methods, in which a perturbing impulse, such as a controlled potential increment, is applied to the system under investigation and the resulting transient response of the system is measured, perhaps as a current flow; reaction types so studied include free radical dimerization and carbanion protonation. The third type concerns the rates of heterogeneous reactions involving electron or charge transfer across the solution-electrode interface. Techniques used to determine the kinetic parameters for chargetransfer and coupled chemical reactions have included cyclic voltammetry, potential step chronoamperometry, chronocoulometry, faradaic rectification, phase-selective AC polarography, and pulse polarography.

\section{The coupled electrode-biochemical process}

Chemically modified electrodes. In recent years, research has accelerated on the chemical modification of working electrode materials, e.g., carbon, platinum, gold and semiconductors, in the hope of enhancing selectivity and/or rate of electron transfer between electrode and preselected solutes. These chemically modified electrodes (CMEs) are usually constructed by attaching a functional group to the electrode material surface by covalent bonding, irreversible adsorption, chemisorption, or formation of a polymeric film. Attaching reactants to an electrode offers obvious advantages, e.g., in flow systems and immobilization of a redox mediator.

For example, chemisorption of alkenes on platinum surfaces has been used for the irreversible attachment of amines, carboxylic acid, quinones, surfactants, metal complexes and other groups through an olefin substituent and for the study of their electrochemical responses. The stability of chemisorption is potentialdependent and the chelating ability of the chemisorbed state can be 'switched on and off' by varying the potential applied to the $\mathrm{CME}^{25}$.

Promising applications for surface-bound reactants in analytical chemistry, electrosynthesis, energy conversion, and solid-state electronic displays are being realized. Some representative examples of biological interest will be presented (Heineman and Kissinger ${ }^{26}$ for a more extensive review).

The current-potential relation for linear sweep voltammetry, when reactants and products are confined to the electrode surface, was developed by Laviron ${ }^{27}$,

$\mathrm{I}=\mathrm{n}^{2} \mathrm{~F}^{2} \Gamma_{\mathrm{T}} \mathrm{v} \xi / \mathrm{RT}(1+\xi)^{2}$

where $\Gamma^{\mathrm{T}}$ is the surface concentration (moles $/ \mathrm{cm}^{2}$ ) of the reactant, $\xi=\exp \left[(\mathrm{nF} / \mathrm{RT})\left(\mathrm{U}-\mathrm{U}^{0}\right)\right], \mathrm{U}$ is the electrode potential, and the other symbols have their customary significance. The cathodic and anodic peaks appear at the standard potential, $\mathrm{U}^{0}$, and the peak potential, $I_{p}$, is given by

$\mathrm{I}_{\mathrm{p}}=\mathrm{n}^{2} \mathrm{~F}^{2} \Gamma_{\mathrm{T}} \mathrm{v} / 4 \mathrm{RT}$

To account for non-ideal behavior, Brown and Anson $^{28}$ introduced surface activities in place of surface concentrations in the Nernst equation for an attached couple:

$\zeta=\mathrm{a}_{\mathrm{O}} / \mathrm{a}_{\mathrm{R}}=\gamma_{\mathrm{O}} \Gamma_{\mathrm{O}} / \gamma_{\mathrm{R}} \Gamma_{\mathrm{R}}$

where a, $\gamma$ and $\Gamma$ are the surface activities, activity coefficients and concentrations, respectively and the subscripts indicate the oxidized $(\mathrm{O})$ and reduced (R) forms of the attached state. The ratio $\gamma_{O} / \gamma_{R}$ can be expressed in terms of a single 'non-ideality parameter', which could be evaluated by analyzing the wave shape.

With equation 2, or the corresponding equation modified to account for non-ideal behavior, $\Gamma_{\mathrm{T}}$ can be calculated when $\mathrm{n}$ is known. ESCA and fluorescence studies have confirmed these $\Gamma_{\mathrm{T}}$ values, which are typically $1-3 \times 10^{-10} \mathrm{moles} / \mathrm{cm}^{2}$ for loosely packed monolayer coverage.

Mediator action enhancement. Redox mediators are used to catalyze the oxidation or reduction of substrates when the rate of direct electron transfer between electrode and substrate is slow. Immobilization of the mediator on the electrode surface (equations 4 and 5) increases the rate of turnover between its oxidized (Ox) and reduced (Red) forms by eliminating the requirement of its transport between interface and solution. This turnover becomes rate-limiting at sufficiently large substrate concentrations. $\left(\mathrm{S}_{\mathrm{ox}}\right.$ and $\mathrm{S}_{\text {red }}$ represent the oxidized and reduced forms, respectively, of the substrate.)

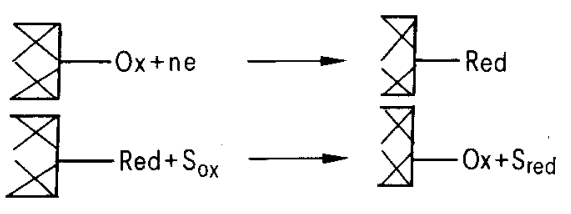

Among the compounds exhibiting rapid, reversible solution redox behavior, which have been attached to electrode surfaces to enhance the rate of electron transfer between electrode and solute, are ferrocene derivatives that have been covalently linked to metal oxide surfaces ${ }^{29,30}$. In many such preparations, linear sweep voltammetry exhibits symmetrical, welldefined waves whose $I_{p}$ are directly proportional to $v$ and whose anodic and cathodic peak $U_{p}$ are nearly identical and independent of $\mathrm{v}$; these waves are due to the one-electron redox of a surface ferrocene/ferricinium charge-transfer state. 
Anson and Brown ${ }^{31}$ used a 9,10-phenanthrenequinone CME prepared by chemical adsorption of the quinone on carbon to study the electron-transfer kinetics between electrode and adsorbed reactant. In the mediator-assisted catalytic scheme (equations 4 and 5), the turnover rate, i.e., the rate at which the catalyst can be cycled between oxidized and reduced states, while catalyzing substrate redox, is of interest. With sufficiently large substrate concentrations, the rate of electron transfer between electrode and attached species will limit the turnover rate. To evaluate such rates, an open-circuit charge-injection 'coulostatic' technique was used: an instantaneous quantity of charge is injected into the CME double layer and the potential-time transients, which reflect consumption of this charge by the redox reaction, are recorded. The rate constant for reduction of the quinone in $1 \mathrm{M}$ $\mathrm{HClO}_{4}$ was evaluated as $320 \mathrm{sec}^{-1}$ at $22^{\circ} \mathrm{C}$; the Arrhenius plot was linear with an intercept (frequency factor) near $\mathrm{kT} / \mathrm{h}$. With this information, it was possible to predict kinetic differences between attached and unattached reactants by rate constant expressions proposed by Marcus ${ }^{32}$ :

$\mathbf{k}_{\mathrm{a}}=\mathrm{A}_{\mathrm{a}} \exp \left(-\lambda_{\mathrm{a}} / 4 \mathrm{RT}\right) \sec ^{-1}$

$\mathrm{k}_{\mathrm{u}}=\mathrm{A}_{\mathrm{u}} \exp \left(-\lambda_{\mathrm{u}} / 4 \mathrm{RT}\right) \mathrm{cm} \mathrm{sec}^{-1}$

where $\mathrm{k}$ is the electron-transfer rate constant, $\mathrm{A}$ is the pre-exponential factor, $\lambda / 4$ is the reorganization energy involved in formation of the transition state, and subscripts $a$ and $u$ denote the attached and unattached reactants, respectively. If $\lambda_{\mathrm{a}}$ is taken to equal $\lambda_{\mu}$, combining equations 6 and 7 then allows comparison of rate constants for the 2 states:

$\mathrm{k}_{\mathrm{a}} / \mathrm{A}_{\mathrm{a}}=\mathrm{k}_{\mathrm{u}} / \mathrm{A}_{\mathrm{u}}$

If $\mathrm{A}_{\mathrm{u}}$ is taken to be $10^{4} \mathrm{~cm} \mathrm{sec}^{-1}$ as for simple adiabatic reactions ${ }^{32}$ and $A_{a}$ is taken as $\mathrm{kT} / \mathrm{h}\left(6 \times 10^{12} \mathrm{sec}^{-1}\right.$ at $25^{\circ} \mathrm{C}$ ),

$\mathrm{k}_{\mathrm{a}}=6 \times 10^{8} \mathrm{k}_{\mathrm{u}} \sec ^{-1}$

Relative catalytic efficiencies of attached and unattached reactants can be predicted with equation 9, given appropriate conditions. Using typical values for the surface and solution concentration of the catalysts, Brown and Anson ${ }^{31}$ predicted that the reaction flux with attached reactants will be several hundred times greater than with unattached catalysts, although several uncertainties are involved. Measurements on other reactants were thought to be necessary before valid generalizations about the kinetic differences between attached and unattached reactants can be made.

By covalently bonding quinones to carbon electrodes whose surfaces had been oxidized with a radiofrequency plasma in an oxygen atmosphere, Tse and
Kuwana $^{33}$ catalyzed the oxidation of NADH and ascorbic acid. $\mathrm{U}_{\mathrm{p}}$ for the $\mathrm{NADH}$ oxidation shifted from $0.55 \mathrm{~V}$ on unmodified carbon to $0.27 \mathrm{~V}$ on the CME. For ascorbic acid, the rate of oxidation by the CME was apparently quite rapid since $U_{p}$ was nearly identical in the presence and absence of ascorbic acid. Thiosilylation of a tin oxide electrode followed by reaction with an iron-sulfur cluster resulted in covalent attachment of the cluster. CMEs so prepared should be useful in investigating the rates of electron transfer via hydrophobic tunnels to biologically important $\mathrm{Fe}_{4} \mathrm{~S}_{4}$ cluster species ${ }^{34}$.

Hemin has been attached to $\operatorname{In}_{2} \mathrm{O}_{3}$ by silanization followed by amidization and direct dehydrative coupling between the hemin carboxyl groups and the $\mathrm{In}_{2} \mathrm{O}_{3}$ surface hydroxyl. The hemin $\mathrm{CME}$ has been applied to the analysis of some oxidants and reductants ${ }^{35}$.

Chiral electrode surfaces. A chiral electrode has been constructed by covalently bonding a compound with a chiral center, (s)-(-)-phenylalanine methyl ester, to the oxidized surface of a graphite rod. Although the attached group, which is bound to the edge plane of the graphite, is not redox active, it functions in tandem with the electron-transfer process to perform an asymmetric reaction on the solute. Modest optical purities were obtained in the reductions of 4-acetyl pyridine and ethyl phenylglyoxylate to the corresponding alcohols ${ }^{36}$ and an anodic asymmetric synthesis of a sulfoxide was reported ${ }^{37}$.

Polymeric film electrode surfaces. In another approach to the modification of electrode surfaces, transition metal complexes have been attached to graphite, which had been coated with polymeric ligands, e.g., by immersion in an alcoholic poly(4-vinylpyridine) solution. Metal complexes, e.g., Ru(III)-EDTA, extracted by the polymer film from aqueous solution, exhibit distorted linear scan voltammetric waves indicating multilayer surface coverage. The oxidation state of the attached complex and crosslinking of ligand residues in the film by the complex can be controlled by suitable selection of potential. The goal is to find combinations of extractable metals, usable polymers and electrode materials, which will yield electrode surfaces with catalytic and analytical uses ${ }^{38}$. The polymer film should be thin to ensure rapid electronic and charge compensating ionic transport in the film when redox reactions occur. However, the coating of porous, crosslinked polymer resins to form rather thick films on electrodes, whose redox reactions are accompanied by easily detectable color changes, has been reported ${ }^{39}$. The charge transfer in the films was thought to occur via movement of electroactive groups in the pores of the resin rather than via mixed valence interactions which give rise to high conductivity in some radical organic solids. These electrodes may be usable in solid-state electronic displays. 
Photocell electrode surfaces. Photocurrents are produced when $\mathrm{SnO}_{2}$ and $\mathrm{TiO}_{2}$ n-type semiconductor anodes, in contact with certain sensitizing dye solutions, are illuminated in the spectral region where the dye absorbs, even though the incident radiation is of less energy than the band gap of the semiconductor. The mechanism of this sensitized current generation is thought to involve injection of charge carriers by the excited state of the dye. When a submonolayer of a sensitizing dye, rhodamine $B$, was covalently attached to $\mathrm{SnO}_{2}$ semiconductor, photocurrents were observed with no dye present in solution ${ }^{40}$. Layers of chlorophyll on optically transparent $\mathrm{SnO}_{2}$ electrodes produce a more efficient, functional photoanode ${ }^{41}$; this semi-biological photocell exhibits improved efficiency when phospholipids instead of neutral fatty acids are used to isolate the chlorophyll molecules in the film, decreasing needless and wasteful transfers of energy between neighbors.

\section{Electrodes coupled to biological processes}

This section deals with the direct insertion of electrodes in biological material in order either a) to monitor analytically the composition or nature of a biological environment or b) to interact with and perhaps to modify a biological environment.

Electrodes as biological monitors. Typical of the imaginative application of contemporary electroanalytical techniques as monitoring agents are the studies of R.N. Adams and his collaborators in neurochemistry and neurobiology involving in vitro and in vivo studies of the catecholamine neurotransmitter system in the mammalian brain, and the possible relationship to neuronal dysfunctioning and mental illness ${ }^{23,42}$. The in vivo studies have involved stereotaxic insertion of micro-voltammetric electrodes (graphite paste and solidified graphite-epoxy resin) in small animal brains to monitor endogenous constituents and injected pharmacological agents, e.g., monitoring of catecholamine metabolites following electrical stimulation of known neural pathways in the brain.

Recently, Blank ${ }^{22}$ examined the regulation of ion transport by the red cell membrane proteins, spectrin and actin, which are present as a layer on the inner face of the membrane. Becker and collaborators ${ }^{43}$ have potentiostatically investigated the impedance of human skin by clamping carbon-impregnated conducting rubber electrodes to regions of interest.

Electrochemical techniques involving insertion of electrodes in regions of concern provide an increasingly valuable approach for elucidating the control of regulatory processes governing cellular activity, e.g., with respect to physiologically significant reactions occurring at a surface or interface such as the outer cell membrane or the junction between cells in organized tissues. A provocative list of accessible problems involving both monitoring and influencing clinical situations is given by Kuwana et al. ${ }^{23}$.

Electrodes as biological modifiers. Several groups of investigators are currently examining the often profound effects seen when electrical stimuli - usually of the order of $\mathrm{nA}$ to $\mu \mathrm{A}$ per $\mathrm{mm}^{2}$ - are applied to living systems, e.g., the growth and repair of damaged bone in a variety of animal types including humans have been clearly shown to be enhanced markedly by the application od DC, pulsed DC and electromagnetically induced currents, using implanted electrodes of tantalum and other noncorrosive materials.

The far-reaching implications of such investigations are evident from the titles of papers presented at the May, 1979, meeting of the Electrochemical Society at sessions on 'Electrochemical Microenvironments and Cell Behavior'22, e.g., 'Cell Surface Electrochemistry and the Regulation of Tissue Growth and Repair', 'Electrical Stimulation of Cartilage Cell Proliferation', 'Electrically Altered Adult Newt Lens Regeneration', and 'Cathode Mediated Bone Proliferation'.

Acknowledgment. The authors thank the National Science Foundation, which helped support the present study.

1 J.J. Lingane, Electroanalytical Chemistry, 2nd edn. Interscience, New York 1958

2 G.E. Baiulescu and V.V. Cosofret, Applications of Ion Selective Membrane Electrodes in Organic Analysis. Halsted, New York 1977.

3 J. Koryta, Analyt. chim. Acta 91, 1 (1977).

4 D.J.G. Ives and G.J. Janz, Reference Electrodes. Academic Press, New York 1961.

5 B.E. Conway, Theory and Principles of Electrode Processes. Ronald, New York 1965.

6 P. Delahay, Double Layer and Electrode Kinetics. Interscience, New York 1965.

7 D.E. Smith, Crit. Rev. analyt. Chem. 2, 247 (1971).

8 T.E. Cummings, W.T. Bresnahan, S.Y. Suh and P.J. Elving, J, electroanalyt. Chem. 106, 71 (1980).

9 M. Katz, T.E. Cummings and P.J. Elving, Ber. Bunsenges. Phys. Chem. 83, 614 (1979).

10 H. Berg, G. Horn and J. Flemming, Studia Biophys. 57, 87 (1976).

11 B. Malfoy, J. M. Sequaris, P. Valenta and H.W. Nürnberg, J. electroanalyt. Chem. 75, 455 (1977).

12 V. Brabec and E. Palecek, J. electroanalyt. Chem. 88, 373 (1978).

13 C.O. Schmakel, K.S.V. Santhanam and P.J. Elving, J. Am. chem. Soc. 97, 5083 (1975).

14 J. Moiroux and P. J. Elving, Analyt. Chem. 50, 1056 (1978).

15 J. Moiroux and P.J. Elving, J. electroanalyt. Chem. 102, 93 (1979).

16 J. Moiroux and P. J. Elving, Analyt. Chem. 51, 346 (1979).

17 G. Dryhurst, Electrochemistry of Biological Molecules. Academic Press, New York 1977.

18 A.L. Underwood and J.N. Burnett, in: Electroanalytical Chemistry, vol.6, pp.1-85. Ed. A.J. Bard. Dekker, New York 1972.

19 E. Palecek, in: Progress in Nucleic Acid Research and Molecular Biology, vol.9, pp.31-73. Ed. J.N. Davidson and W.E. Cohn. Academic Press, New York 1969.

20 P.J. Elving, C.O. Schmakel and K.S.V. Santhanam, Crit. Rev. analyt. Chem. 6, 1 (1976).

21 P.J. Elving, in: Topics in Bioelectrochemistry and Bioenergetics, vol. 1, pp. 180-286. Ed. G. Milazzo. Wiley, London 1976.

22 Electrochemical Society, Meeting May 1979, abstracts, J. electrochem. Soc. 126, 140C-143C (1979) 
23 T. Kuwana, ed., Workshop on Bioelectrochemistry: January 1976. Ohio State University, Columbus 1976.

24 P.J. Elving and B. B. Graves, in: Topics in Bioelectrochemistry and Bioenergetics, vol.3, in press. Ed. G. Milazzo. Wiley, London.

25 R.F. Lane and A. T. Hubbard, J. Phys. Chem. 77, 1401, 1411 (1973).

26 W. R. Heineman and P.T. Kissinger, Analyt. Chem. 50, 166R (1978).

27 E. Laviron, Bull. Soc. chim. Fr. 1967, 3717.

28 A.P. Brown and F.C. Anson, Analyt. Chem. 49, 1589 (1977).

29 J.R. Lenhard and R. W. Murray, J. Am. chem. Soc. 100, 7870 (1978).

30 D.F. Smith, K. Willman, K. Kuo and R.W. Murray, J. electroanalyt. Chem. 95, 217 (1979).

31 A.P. Brown and F.C. Anson, J. electroanalyt. Chem. 92, 133 (1978).

32 R.A. Marcus, J. Chem. Phys. 43, 679 (1965)

33 D.C. Tse and T. Kuwana, Analyt. Chem. 50, 1315 (1978).
34 Commun. 940 (1976).

35 S Suzuki, M. Karayama and S Araki, American Chemical Society, Division of Analytical Chemistry, Abstract No. 105, Honolulu, April 1979.

36 B.F. Watkins, J.R. Behling, E. Kariv and L. L. Miller, J. Am. chem. Soc. 97, 3549 (1975).

37 B.E. Firth, L. L. Miller, M. Mitani, T. Rogers, J. Lennox and R.W. Murray, J. Am. chem. Soc. 98, 8271 (1976).

38 N. Oyama and F.C. Anson, J. Am. chem. Soc. 101, 739 (1979).

39 F.B. Kaufman and E.M. Engler, J. Am. chem. Soc. 101, 547 (1979).

40 T. Osa and M. Fujihira, Nature 264, 349 (1976).

41 T. Miyasaka, T. Watanabe, A. Fuyishima and K. Honda, Nature 277, 638 (1979)

42 R.N. Adams, Analyt. Chem. 48, 1126A (1976).

43 M. Reichmanis, A.A. Marino and R.O. Becker, J. electrochem. Soc. 125, 1765 (1978).

\section{General energetic criteria for the implementation of electrochemical, chemical and biochemical electron transfer processes}

by René Buvet

Université Paris Val de Marne, Laboratoire d'Energétique Electrochimique et Biochimique, Avenue du'Général de Gảulle, F-94010 Créteil Cédex (France)

This article aims at summarizing the criteria based on energetic data and kinetic rules of general validity which can be utilized to predict the feasibility of a given chemical redox process, particularly by enzymatic catalysis, and to determine the physico-chemical conditions related to the state of the solution where reagents are present which could restrain this feasibility.

When applying these criteria to the whole field of carbon chemistry in aqueous solutions, at room temperature and in the medium $\mathrm{pH}$ range, one is led to the conclusion that the feasible redox processes are actually much less diverse than is currently assumed without serious examination. As a matter of fact, the chemistry of life is more or less identifiable in this respect with the whole range of remaining physicochemical possibilities, without any need for qualitative supplementary restrictions, leading, e.g., to some sort of discrimination made by enzymatic sequences randomly settled by evolution. Enzyme catalysts, which are often considered to be the qualitatively determining factors of the choice of metabolic processes, are in fact only executive agents, more or less discriminative, for the whole set of processes that remain feasible when the energetic and kinetic redox reactivity of concerned substrates is correctly analyzed.

\section{Stoichiometry of redox reactions}

Oxido-reduction, or redox reactions, are usually defined as chemical transformations which can be globally described by stoichiometrically summing up the following:

a) the capture of one or several electrons by a reagent called the oxidant of the electron-accepting redox couple (1)

$\mathrm{a}_{1} \mathrm{Ox}_{1}+\mathrm{n}_{1} \mathrm{e}^{-}+\mathrm{p}_{1} \mathrm{H}^{+} \leftrightharpoons \mathrm{b}_{1} \operatorname{Red}_{1}+\mathrm{q}_{1} \mathrm{H}_{2} \mathrm{O}$;

b) the supply of one or several electrons by another reagent called the reductant of the donor redox couple (2):

$\mathrm{a}_{2} \mathrm{Red}_{2}+\mathrm{q}_{2} \mathrm{H}_{2} \mathrm{O} \leftrightharpoons \mathrm{b}_{2} \mathrm{Ox}_{2}+\mathrm{n}_{2} \mathrm{e}^{-}+\mathrm{p}_{2} \mathrm{H}^{+}$

Some redox couples involve other compounds, such as $\mathrm{NH}_{3}$ in aminating reductions of $a$-ketoacids or aldehydes, and $\mathrm{HS} \mathrm{COA}$ in thioesterifying oxidation of aldehydes. But such cases are better treated by complementary modifications of the theory involving additions of non-redox processes to redox couples defined as proposed above.

In fact, we will have to distinguish between the different kinds of stoichiometry of redox couples as to whether they involve

- either simply one or several electrons, as:

$\mathrm{Ox}+\mathrm{ne}^{-} \leftrightharpoons \mathrm{Red}$

such as in: $\mathrm{Fe}^{3+}+\mathrm{e}^{-} \leftrightharpoons \mathrm{Fe}^{2+}$.

- or a proton-exchange in addition to the electron exchange as:

$\mathrm{Ox}+\mathrm{ne}^{-}+\mathrm{pH}^{+} \leftrightharpoons \mathrm{Red}$ 